STUDI

FRANCESI

\section{Studi Francesi}

Rivista quadrimestrale fondata da Franco Simone

190 (LXIV | I) | 2020

Varia - fasc. I - gennaio-aprile 2020

\title{
ALFRED DE VIGNY, Théâtre complet
}

\section{Esther Pinon}

\section{OpenEdition \\ Journals}

Édition électronique

URL : https://journals.openedition.org/studifrancesi/22851

DOI : 10.4000/studifrancesi.22851

ISSN : 2421-5856

\section{Éditeur}

Rosenberg \& Sellier

\section{Édition imprimée}

Date de publication : 1 avril 2020

Pagination : 191

ISSN : 0039-2944

\section{Référence électronique}

Esther Pinon, "ALFRED dE VIGNY, Théâtre complet », Studi Francesi [En ligne], 190 (LXIV | I) | 2020, mis en ligne le 01 mai 2020, consulté le 03 août 2021. URL : http://journals.openedition.org/studifrancesi/ 22851 ; DOI : https://doi.org/10.4000/studifrancesi.22851

Ce document a été généré automatiquement le 3 août 2021.

\section{(c) (†)}

Studi Francesi è distribuita con Licenza Creative Commons Attribuzione - Non commerciale - Non opere derivate 4.0 Internazionale. 


\title{
ALFRED DE VIGNY, Théâtre complet
}

\author{
Esther Pinon
}

\section{RÉFÉRENCE}

ALFRED DE VIGNY, Théâtre complet, éd. S. Ledda et L. Sabourin, Paris, Classiques Garnier, 2018, 1047 pp.

1 Alors que le théâtre de Hugo et de Musset est régulièrement revisité par les metteurs en scène contemporains, celui de Vigny n'est plus guère représenté à la scène. L'édition qu'en offrent Sylvain Ledda et Lise Sabourin permet de mesurer à quel point cet oubli est regrettable. Elle met en effet en lumière les qualités littéraires et scéniques des «compositions d'après Shakespeare» (Roméo et Juliette, Le More de Venise, Le Marchand de Venise), de La Maréchale d'Ancre, de Quitte pour la peur et de Chatterton en les resituant dans leur contexte esthétique et culturel, avec une attention aiguë à leurs conditions de publication et de représentation, sans pour autant en négliger les enjeux philosophiques, sociaux et politiques. Sylvain Ledda et Lise Sabourin rappellent que Vigny fut un acteur majeur de la révolution romantique, ancré dans son temps, à rebours de l'image stéréotypée du poète retranché en sa tour d'ivoire, et le démontrent par une approche qui renouvelle l'analyse de son activité dramaturgique, ainsi que par la mise au jour de documents jusqu'ici inaccessibles. L'édition a en effet bénéficié de l'acquisition par la Bibliothèque nationale de France du More de Venise, dont l'étude permet d'affiner la connaissance de cette pièce qui fut l'un des événements majeurs de la «bataille» romantique.

2 L'introduction générale du volume propose de voir dans le théâtre de Vigny un «laboratoire des genres" en même temps qu'un «miroir d'idéal» (pp.12-17), hypothèse particulièrement convaincante en ce qu'elle révèle la hauteur de vue d'un dramaturge attaché à donner corps, sur les planches, à une pensée qui dépasse largement les préoccupations immédiates de l'actualité théâtrale, sans pour autant jamais négliger les réalités concrètes du plateau et de la salle. Une relecture très attentive de la «Lettre à Lord ${ }^{* * *}{ }_{»}(\mathrm{pp} .127-135)$ montre notamment que, s'il ne cherche 
pas à se soumettre à tout prix aux attentes du public, Vigny en a une conscience très fine et les utilise pour mieux les dépasser. Les planches lui sont ainsi un véritable tremplin, une voie d'élévation.

3 Tout en s'appuyant sur les apports des éditions précédentes, et en particulier sur la précieuse étude génétique menée par François Germain et André Jarry pour la Pléiade en 1986, Sylvain Ledda et Lise Sabourin posent ainsi un regard neuf sur le théâtre de Vigny, grâce à un apparat critique très dense. À l'image de l'importante introduction du volume, extrêmement documentée et qui ne laisse dans l'ombre aucun aspect de la carrière de Vigny dramaturge, la présentation de chaque pièce constitue à soi seul un petit essai qui éclaire non seulement la création, les enjeux et la réception des œuvres, mais aussi la souplesse de la poétique de Vigny. Tout en conservant une très grande cohérence, celle-ci fait en effet l'objet d'une perpétuelle réinvention, que Sylvain Ledda et Lise Sabourin donnent à voir avec précision et passion. De l'exploration du geste créateur via l'imitation dans les "compositions d'après Shakespeare» jusqu'à l'invention d'une forme inédite, véritable saisie du réel par l'épure, avec le «drame de la pensée» qu'est Chatterton, en passant par la quête d'une écriture de l'histoire qui en préserve la vérité par l'ouverture du sens dans La Maréchale d'Ancre, et par la ressaisie du genre du proverbe, devenu réceptacle de questionnements sociaux, dans Quitte pour la peur, c'est la remarquable exigence d'une incessante expérimentation intellectuelle et artistique qui se dessine. La grande rigueur scientifique avec laquelle sont établies les variantes et reproduites les esquisses laissées par Vigny (esquisses de Chatterton, mais également de nombreux projets théâtraux demeurés à l'état de rêve), vient encore renforcer la démonstration: elle offre au lecteur un accès direct à l'intense travail créateur qui préside chez Vigny à l'écriture théâtrale, nourrie d'un va-et-vient perpétuel entre l'expérience de la scène et la pensée théorique du drame.

Le volume offre enfin une riche bibliographie, ainsi qu'un index des œuvres citées et un index des personnages qui faciliteront aux lecteurs et aux chercheurs l'usage de ce qui constitue désormais, à n'en pas douter, l'édition de référence du théâtre de Vigny. 